\title{
DESCENTRALIZAR, CONTRACTUALIZAR: EL NUEVO MARCO DE LA GOBERNANZA MULTINIVELES
}

Luis Arturo de la Torre Sendoya*

\section{Resumen}

Este artículo propone un análisis de la trayectoria inicial de la descentralización en Colombia marcada por la afirmación del ámbito local a través de la noción de autonomía, y una reflexión prospectiva en la nueva etapa que se abre con el posconflicto, en la que se impone una gobernanza territorial multiniveles más inclusiva para el buen manejo del desarrollo regional utilizando el nuevo instrumento de acción pública, Contrato Plan.

Palabras clave: descentralización, autonomía, planificación territorial, gobernanza territorial multiniveles, contratos plan, posconflicto.
DECENTRALIZATION: THE NEW MULTILEVEL GOVERNANCE FRAMEWORK Abstract

This paper analyses the initial Colombian decentralization path marked by the empowerment at local level through the notion of autonomy, and provides a prospective reflection related to the new and emerging post-conflict phase, which focuses on inclusive territorial multi-level governance for the good management of regional development using the new public policy tool - Contrato Plan (Planning Contract).

Key words: Decentralization, autonomy, territorial planning, territorial multi-level governance, contrato plan, post-conflict.

\footnotetext{
* Master en Ciencias Sociales. Investigador asociado Laboratorio ART-Dev (Acteurs, Ressources et Territoires dans le Développement), Universidad Montpellier III, Montpellier (Francia).[luisar1@yahoo.fr].

Recibido: 27/10/2016/ Modificado: 15/05/2017/ Aceptado: 01/06/2017.

Para citar este artículo

De la Torre Sendoya, L. A. (2017). Descentralizar, contractualizar: el nuevo marco de la gobernanza multiniveles. OPERA, 21, pp. 95-112.

DOI: https://doi.org/10.18601/16578651.n21.06
} 
La descentralización es más que un principio constitucional intangible de la institucionalidad colombiana. En los últimos treinta años ha sido el principal factor de transformación de las instituciones, de la gestión pública y de la manera de hacer política en el país. Resumiendo lo que se ha producido durante este periodo podríamos decir que la descentralización ha generado un proceso de atribución a los niveles de gobierno subnacionales (cuyos representantes son elegidos por el sufragio popular) del poder de decisión sobre la naturaleza, el contenido y la ejecución de buena parte de las políticas públicas que se implementan en los territorios, con base en un sistema más o menos consolidado de repartición o transferencia de competencias y recursos entre las autoridades públicas del Estado.

Es cierto que este decorado institucional en el que se desarrolla hoy la política y la acción pública en nuestro país, fruto de una evolución legislativa anterior a la Constitución del 91, y del nuevo marco constitucional que allí se define, ha sido desdibujado o alterado por el impacto local del conflicto interno. Pero, aun así, con respecto a la Colombia de los arreglos bipartidistas cerrados y del centralismo bogotano inapelable de los años sesenta a ochenta, la progresiva implementación de la descentralización ha forjado una pautada revolución política e institucional que transformó radicalmente el país político y la sociedad colombiana.

El objeto de este artículo no es hacer el balance de este proceso que varios textos retoman bajo sus diferentes componentes (descentralización fiscal, administrativa, política y territorial) en análisis con enfoques en su mayoría sectoriales, menos frecuentemente con una visión integrada de la organización de la acción pública en nuestro país ${ }^{1}$. Nuestro enfoque se inscribe en la perspectiva de los estudios sobre la territorialización de la acción pública que ha desarrollado particularmente la ciencia política cognitiva francesa (Négrier, 2007 $)^{2}$. Esta manera de abordar el tema de la acción pública entre politics y policy, plantea la hipótesis de la "territorialidad" de la acción colectiva fijando una línea de ruptura en relación con las diferentes declinaciones de lo "local" (acción pública local, políticas públicas locales, administración local, poder local, gobierno local, desarrollo local) (Faure, 2011). La ambición de este enfoque es proponer una nueva comprensión de la articulación entre descentralización y gobernanza que pone a distancia algunas "evidencias" que caracterizan

1 Citamos en este texto y en la bibliografía de este artículo varios trabajos de tipo sectorial, indispensables para la comprensión de un fenómeno histórico complejo, los cuáles contrastamos con la exhaustiva investigación doctoral del politólogo Alberto Maldonado Copello, Los limites de la descentralización territorial: el caso de Colombia 1991-2008 (2012), cuyo subtítulo, "Las promesas incumplidas de la descentralización territorial en Colombia” refleja bien el enfoque integrado y crítico del autor. En un registro colectivo, nos referimos igualmente al balance 25 años de descentralización en Colombia, publicado en abril de 2010 por la Fundación Konrad Adenauer, que aporta cuatro contribuciones temáticas igualmente mencionadas en este texto sobre los problemas institucionales, territoriales y de seguridad que plantea la descentralización. Hemos hecho uso, también, de un informe (no publicado hasta la fecha) de Andrés Castro Forero (2014) para la ESAP cuyo contenido analítico nos parece particularmente pertinente.

2 Para fijar el marco de esta propuesta científica recomendamos la lectura de los diferentes artículos del Dictionnaire des politiques territoriales (Pasquier et al., 2011). 
el discurso científico y político sobre la descentralización, en particular las aserciones sobre las virtudes intrínsecas de democratización, economías de escala y eficiencia que aportaría per se la descentralización. En este enfoque juega un papel importante la noción de gobernanza entendida como "un proceso de coordinación de actores, de grupos sociales y de instituciones, cuya perspectiva es obtener resultados definidos y deliberados colectivamente" (Le Galès, 2010, p. 301). La gobernanza orienta la reflexión hacia el conjunto de instituciones, redes, reglamentaciones, normas, arreglos políticos y sociales que contribuyen a la estabilidad o volatilidad de un régimen político o de una sociedad, y a su capacidad a producir bienes y servicios que le dan legitimidad.

Hoy, cuando la agenda política impone en Colombia la construcción de nuevos escenarios para el posconflicto, proponemos una revisión sintética de la trayectoria inicial de la descentralización colombiana marcada por los límites y los impases de la afirmación del ámbito local a través de la noción de "autonomía". Del análisis de este contexto emerge una reflexión prospectiva sobre lo que podría ser una nueva etapa de ese proceso que se apoyaría en nuevos instrumentos de acción pública propios del paradigma de la gobernanza multiniveles para enfocar los retos políticos y territoriales del desarrollo regional, y en particular uno de reciente creación que estudiamos en su evolución reciente, los Contratos Plan.

\section{EL PULSO ENTRE LA CAPITAL Y LAS "PROVINCIAS"}

Hasta el comienzo de los ańos ochenta, la historia colombiana había construido una democracia centralista con un régimen de partidos de despliegue regional (Tirado, 1983; Leal, 1984). Esta configuración político-territorial es probablemente la matriz aún dominante del sistema político colombiano (Chambron, De la Torre, 1994). Pero en las décadas de los ochenta y noventa Colombia inicia un proceso que abre el paso a la expresión de una mayor autonomía regional y participación comunitaria.

El diagnóstico oficial de un Jaime Castro, en aquel entonces (1984) ministro del interior ${ }^{3}$, ponía en relación el excesivo grado de centralización del Gobierno (que se manifestaba en la concentración de los ingresos tributarios en el nivel central-nacional) y la burocratización de la acción pública (factor causal de la corrupción y del despotismo locales), con la incapacidad del Estado para atender las necesidades de la población en la mayoría de los municipios que se traducía, a su vez, en el malestar ciudadano expresado en la protesta social, caldo de cultivo de la insurgencia guerrillera.

Como en el resto de América Latina, en aquel entonces en plena fase de transición democrática y bajo el yugo generalizado de la hiperinflación, la ola de reformas descentralizadoras y del Estado abarca en nuestro país

\footnotetext{
Que se expresa constantemente en la obra y acción pública de este liberal atípico, identificado con una reinvención del federalismo (Castro, 2003).
} 
dos objetivos, uno político y otro económico (Marcou, 2008). El primer objetivo responde al imperativo de propiciar un mayor protagonismo del Estado en los escenarios donde la huella de la acción pública es más endeble y menos eficiente, los niveles local y regional, donde solo los actores de la política regional y los protagonistas del conflicto hacen presencia, a veces exclusiva y arbitraria (Leal, Dávila, 1991). El segundo busca responder a la demostración que hace en 1982 el informe Bird-Wiesner sobre las finanzas intergubernamentales: la concentración de los recursos financieros del sector público en el nivel nacional, en detrimento de los niveles locales que constituye, aún hoy, el talón de Aquiles de la gobernanza pública colombiana. El proyecto descentralizador que propicia este informe plantea las bases de una reorganización de la administración territorial que busca reducir el impacto de los déficits fiscales del Estado (Rojas, Moncayo, 1989), comprometiendo a los ejecutivos locales en la prestación de los servicios públicos bajo el supuesto de que el juego de las transferencias de competencias y de las participaciones presupuestales a los gobiernos locales permitiría mejorar la calidad de servicio y la cobertura de la población ${ }^{4}$.

Si sobrevolamos el impacto de la legislación y las medidas de descentralización que tomaron los diferentes gobiernos de las tres décadas del tránsito del milenio, y sus consecuencias en materia de gestión pública (González
Salas, 1997), podríamos resumir el proceso descentralizador colombiano en dos ciclos que corresponden a dinámicas invertidas:

- Una primera etapa consistió en un doble proceso de democratización a través de la elección por sufragio universal de los ejecutivos de las entidades locales 5 reconocidas de esta manera en su condición de personas jurídicas territoriales, y de la transferencia de atribuciones y recursos, corolario de una repartición de competencias entre el Gobierno nacional y el nivel local. Es un movimiento claramente centrífugo, iniciado a principio de los años ochenta, con la descentralización administrativa (1978-1982), y el esfuerzo posterior de delegación y simplificación de la gestión pública que asigna a las entidades territoriales la función de prestación de servicios públicos a la población (educación, salud, saneamiento y agua potable, y recolección de basuras), y de fortalecimiento del nivel departamental. Su implementación se fortaleció en la arquitectura institucional de la Constitución del 91. Sin embargo, la ampliación de los espacios de participación democrática de los ciudadanos, a excepción de los grupos culturales minoritarios convocados al arbitraje en la realización de proyectos de desarrollo de impacto territorial por diferentes mecanismos de

\footnotetext{
4 Diez años después, Eduardo Wiesner (2003) hará un balance ambivalente del efecto de las medidas descentralizadoras tomadas en los diferentes países de América Latina y en Colombia, en particular para corregir este desequilibrio estructural.

5 Con el Acto legislativo 1, del 9 de enero de 1986, que permita la elección por voto popular de los alcaldes.
} 
consulta previa, ha sido más formal que efectiva (Melo, 2011). En este mismo campo del acercamiento de los ciudadanos a la decisión pública también queda suspendida en la agenda institucional la evolución del mapa político del país, con la anunciada y constantemente pospuesta hasta la fecha creación de regiones.

- En la segunda etapa, los gobiernos y los planes nacionales de desarrollo de los años 2000 a 2010 establecieron las bases de un movimiento centrípeto de signo inverso al de las décadas anteriores a los ochenta y noventa. Leyes como la Ley 489 de diciembre de $1998^{6}$, pero igualmente la reforma de la carrera administrativa, la transformación del régimen del presupuesto público y de la administración tributaria, y la reformulación de la articulación sectorial del Estado mediante la redefinición de competencias ministeriales, el fortalecimiento de la planeación, el desarrollo de sistemas de información y seguimiento del desempeño organizacional (Gutiérrez Sanín, 2010) ${ }^{7}$, cambiaron la orientación del proceso. Si a ello le sumamos el nuevo "equilibrio jerárquico" 8 que caracterizó las relaciones entre el nivel central y los gobiernos subnacionales durante las dos administraciones de Álvaro Uribe, es claro que desde hace dos décadas se ha buscado reestructurar el Estado y rediseñar los sistemas de gestión pública a partir de dinámicas de recentralización.

En esta evolución pendular, el diálogo político entre la nación y el país profundo de los territorios se forjó en la estricta asimilación de dos conceptos de ámbito de aplicación constitucional que constituyen hoy generalmente la ecuación y el filtro a través del cual se leen buena parte de los procesos políticos colombianos, a saber: "descentralización = autonomía territorial". De esta manera, todo proyecto de afirmación del principio descentralizador se ha concebido obligatoriamente como un paso encaminado a ampliar la autonomía de las entidades territoriales y de sus ejecutivos.

$\mathrm{Al}$ respecto es bueno recordar que los procesos descentralizadores son observables en todo el mundo (World Bank Group, s.f.), y que prácticamente en todos los contextos, la descentralización se percibe igualmente como el mejor antídoto a la concentración de los poderes en un mismo lugar, y como el proceso antinómico del centralismo, considerado como antidemocrático per se (Davezies y Morvan, 2016). No vamos a entrar a calificar la pertinencia de esta representación binaria y simplificada del Estado que domina el análisis de las políticas públicas a nivel político y académico, pero queda claro que Colombia no escapa al síndrome del pulso entre "centro" y

\footnotetext{
6 "Por la cual se dictan normas sobre la organización y funcionamiento de las entidades del orden nacional".

Cfr., en particular, el Acto legislativo 1 de 2001, que modifica los artículos 356, relativo a los "servicios a cargo de la Nación y las entidades territoriales", y 357 sobre "la participación en los ingresos corrientes de la Nación”, de la Constitución.
}

8 Según el término que emplea el analista de la ONG Foro Nacional por Colombia, Fabio Velásquez (2006). 
"periferia" que caracteriza los procesos descentralizadores de todos los países desarrollados.

En nuestro caso, en ese tire y afloje, la respuesta a los desafíos de la modernización de la administración pública se concibió en su momento siguiendo los parámetros de la Nueva Gestión Pública' en la que casi siempre prima la dimensión nacional del desarrollo, bajo el imperativo de la gestión pública sectorial, es decir, una organización del gasto público por "sectores ministeriales" como la educación, la vivienda, la justicia, la defensa nacional. Esto no impidió que, al mismo tiempo, una progresiva regionalización de la planificación, que evocaremos posteriormente, permitiera plantear la necesidad de territorializar el gasto público. El resultado apenas paradójico es que, al término del proceso, y en particular a partir del Plan Nacional de Desarrollo 2010-2014, los municipios y los departamentos absorben cerca del $40 \%$ de los ingresos corrientes de la nación, reciben la casi totalidad de recursos del Sistema General de Regalías y ejecutan el 64\% de la inversión total del país (MaldonadoCopello, 2011).

En consecuencia, parecería que las entidades territoriales cuentan con las competencias y los recursos para responder a los desafíos del desarrollo regional. Sin embargo, en la república unitaria que prevalece en el ordena- miento político de la Constitución del 91, el determinismo centralizador sigue siendo preponderante pues los recursos de las entidades territoriales siguen procediendo en gran parte de transferencias y participaciones. Y aunque el federalismo fiscal ${ }^{10}$ es una de las fuentes indiscutibles de los procesos de descentralización en América Latina, y en Colombia en particular ${ }^{11}$, los recursos propios de las entidades territoriales, producto de la tributación o de la repartición del Sistema General de Regalías (sGR), no son propiamente de libre administración pues su afectación debe responder prioritariamente a la cobertura de los servicios públicos a la población. Asociados a esta circunstancia, el impacto local del conflicto y la deficiente gestión de las administraciones territoriales resultante de la captura de los aparatos políticos, el clientelismo y la corrupción (Garay Salamanca y Salcedo-Albarán, 2010), han congelado el diálogo político perennizando la retórica del enfrentamiento estéril entre las élites de la capital y las de las "provincias", en una interminable tragicomedia que poco coincide con la complejidad de los problemas de desarrollo local del país.

La actual coyuntura de preparación e implementación de las políticas públicas que deben responder a los desafíos del posconflicto parece el momento adecuado para abandonar

9 Inspirada en el célebre libro de David Osborne y Ted Gaebler, Reinventing Government: How the Entrepreneurial Spirit Is Transforming the Public Sector (1993) (Cruz, 2009).

10 Es decir, el análisis de "las funciones económicas que deben desarrollar los distintos niveles de gobierno y los instrumentos fiscales apropiados para desarrollar dichas tareas, con el objetivo de lograr una provisión y financiación eficiente de bienes públicos" (Franco y Cristancho, 2012, p. 238).

11 Recordemos el papel que jugó en 1968, durante el Gobierno de Alberto Lleras Camargo, la "Misión Musgrave", presidida por Richard Musgrave uno de los teóricos del federalismo fiscal, en la preparación de una de las primeras reformas tributarias de corte descentralista en Colombia. 
esa dinámica conflictiva que marcó la primera descentralización colombiana, y dar paso a una visión más colaborativa del diálogo entre la nación y sus territorios. Este propósito nos parece hoy viable si consideramos, tal como proponemos analizarlo en el desarrollo de este documento, que en la doctrina del Estado constitutiva de los instrumentos de acción pública concebidos para aplicar los programas de desarrollo territorial del posconflicto aparecen dos parámetros importantes en el manejo del desarrollo regional, la noción de "territorio" y el paradigma metodológico del "proyecto", sobre los cuales podría fundarse una nueva etapa de la descentralización.

\section{LOS DESAFÍOS TERRITORIALES DEL DESARROLLO}

La irrupción de la "cuestión territorial" en el debate sobre la gobernanza pública es un fenómeno que rebasa la descentralización política y administrativa colombiana. El punto de partida teórico es el postulado de que toda actividad humana está localizada territorialmente, es decir, ambientada en un espacio y un entorno social singulares. Esta manera de referenciar territorialmente la relación social, en el sentido weberiano de la expresión ${ }^{12}$, no puede depender de una geografía inmanente ya que el "territorio" es una construcción social, económica y política, y no un marco normativo instalado en una realidad física predeterminada (Auriac y Brunet, 1986). De alguna manera, la noción de "territorio" es el principal "descubrimiento" de la ciencia regional en los últimos treinta ańos, y en la dialéctica global/local aparece como el "reverso" virtuoso y deseable de la mundialización (Lamara, 2009). La hipótesis fundamental subyacente a esta geografía del desarrollo que estructura en Europa desde los años noventa la denominada "escuela de la proximidad" (Gilly y Torre, 2000) es que "el territorio es el producto social de un proceso de coordinación de actores reunidos para resolver un problema productivo inédito y de la construcción de recursos territoriales que se activan (o se revelan) por una dinámica renovada de territorio" (Lamara, 2009, p. 4).

$\mathrm{Al}$ adoptar esta manera de pensar el territorio, la concepción y la implementación de las políticas de desarrollo no pueden predeterminarse a partir de las circunscripciones político-administrativas. La escogencia de los ámbitos territoriales pertinentes para organizar la acción pública se define o escoge "a la carta" como el resultado de un juego de actores en el cual la delimitación misma de la escala territorial (su espacio físico, sus fronteras, sus componentes humanos, ambientales e históricos) forma parte de la interacción que impulsa la dinámica del proyecto. El territorio de la acción es, en sí mismo, "proyecto" y factor de realización de la acción.

En la práctica, Colombia no escapa a esta revolución política y cultural ya que desde hace más de una década, en materia de programación del desarrollo, en nuestro país coexisten los territorios tradicionales de la representación

\footnotetext{
12 "Por relación social debe entenderse una conducta plural - de varios- que, por el sentido que encierra, se presenta como recíprocamente referida, orientándose por esa reciprocidad” (Weber, 1922, p. 21).
} 
política (municipios, departamentos) que trazan las fronteras de la planeación y del ordenamiento presupuestal, con nuevas construcciones territoriales que dibujan perímetros inéditos de intervención, concebidos para la implementación de programas que despliegan las políticas públicas del Estado sin coincidir obligatoriamente con los territorios de la arena político-electoral. Por eso se pueden mencionar los espacios de implementación de ciertas políticas estratégicas del primer Gobierno Santos, como las Zonas de Consolidación de la Paz del Plan Nacional de Desarrollo (PND) 2010-2014, "Prosperidad para todos", que se aplicaron en áreas como los Montes de María o el golfo de Urabá y el área del Gran Darién, territorios que por evidentes razones de eficiencia respecto a la problemática del conflicto -el problema que buscaban transformar-, no podían limitarse a las fronteras departamentales clave de lectura de la división político-administrativa del Estado.

De manera que hemos entrado en una fase en la que la legitimidad o el valor agregado para el desarrollo regional de un ámbito territorial determinado no pueden ser juzgados por su posicionamiento institucional o su jerarquía constitucional que determinarían a priori el grado de autonomía que se les debe atribuir a las entidades públicas y a sus representantes. Los desafíos del desarrollo regional han llevado a los actores del desarrollo (políticos, técnicos, personal administrativo, empresarios privados, población y actores sociales) a valorar la pertinencia de la acción pública con base en criterios de gestión que permiten construir lo que se debería llamar "proyectos de territorio". Entre estos criterios se toman en cuenta, en particular, la factibilidad técnica y política de la inversión, la eficiencia del gasto, y el impacto sobre el medio ambiente y sobre la población de un espacio territorial determinado.

Si hacemos la genealogía del policy making de esta evolución observamos que es con base en este enfoque que el Departamento Nacional de Planeación ha ido incorporando progresivamente la dimensión territorial en la concepción de los instrumentos de planificación del desarrollo. La primera etapa, en la década de transición del siglo, fue la promoción de la dimensión departamental del desarrollo, que llevó a imponer esta escala territorial como el espacio idóneo para caracterizar las situaciones de vulnerabilidad social o de desigualdad territorial (DNP, 2008). En el mismo impulso, el Gobierno departamental se impuso como la instancia política de acción para disminuir las brechas regionales y generar dinámicas endógenas de desarrollo. Luego vino la afirmación de la necesidad de formular políticas regionales diferenciadas dentro del Plan de Desarrollo, de la cual emerge, por ejemplo, el concepto de Área de Desarrollo Territorial (DNP, 2013). En todo este proceso juega un papel decisivo la Dirección de Desarrollo Territorial de esta institución ${ }^{13}$.

El resultado tangible es que a partir del PND 2010-2014, "Prosperidad para todos", se ha buscado formalizar una política regional integral. En ella se toman en cuenta, por

13 Que tuvo durante 17 años (y esto, de por sí, es una excepción en la alta administración del Estado) el mismo director con el mismo equipo directivo y de asesores. 
un lado, los planes maestros sectoriales que coinciden generalmente con las divisiones político-administrativas (por ejemplo, los planes departamentales de agua, $\mathrm{y}$ las comisiones regionales de competitividad, ambos inscritos en el perímetro de acción departamental de las gobernaciones). Por otra parte, se da prioridad a iniciativas con arraigo infra o intermunicipal, que no respetan obligatoriamente los entornos departamentales dibujando un mapa de espacios inter o pluridepartamentales. Algunas buscan, por ejemplo, estructurar una producción económica localizada a través de la fórmula de los clústeres que crean dinámicas de producción $y$ de competitividad territorial ${ }^{14}$. Otras generan una intervención preventiva para preservar el medio ambiente a través de parques naturales regionales o esquemas de gestión de cuencas hidrográficas, por ejemplo. La característica común de estas iniciativas es que para su implementación la coordinación de los actores parte de los recursos territoriales llegando así a emanciparse del cerco cerrado de la división político-administrativa.

\section{AUTONOMÍA FRENTE A COORDINACIÓN, EL RETO DE LA GOBERNANZA MULTINIVELES}

Como decíamos, hoy se admite cada vez más que el buen manejo del desarrollo territorial debe cumplir una serie de requisitos en materia de gestión de los recursos públicos y de participación ciudadana. Uno de los nudos gordianos del problema es: ¿cómo organizar u ordenar la coordinación interinstitucional entre las diferentes instancias que participan en el desarrollo social y económico del país?

La optimización de la acción pública para el desarrollo ha planteado, incluso antes del comienzo de la descentralización política de los años ochenta, dos respuestas complementarias: la territorialización del ejercicio de planeación para que la distribución de la inversión pública tome en cuenta las diferentes dimensiones de la realidad de los territorios; y el fomento de la asociatividad entre entidades territoriales para que sean las autoridades locales las que generen procesos endógenos de desarrollo territorial integrado.

En la primera orientación hay que recordar el papel decisivo que jugaron los consejos regionales de planificación (CORPES), que constituyen uno de los precedentes más importantes del esquema de articulación institucionalizada entre la nación y los departamentos, y tenían como propósito central lograr la integración y el desarrollo territorial en nuestro país (Chamorro, 1997). Se crearon como parte del proceso de descentralización o por iniciativa de las propias regiones, y desempeńaron durante más de una década (1985-2000), en varios territorios de la geografía nacional ${ }^{15}$, funciones que podríamos llamar "técnicas" y "políticas" en el ámbito de la planificación: entre las primeras, planificar el desarrollo equilibrado de las regiones, preparar planes

\footnotetext{
14 Por ejemplo, los proyectos de integración productiva y de desarrollo turístico del Eje Cafetero.

15 En particular, en la Costa Atlántica, la región Occidente (Pacífico), y las zonas de los en aquel entonces denominados "territorios nacionales"-Amazonia y Orinoquia-.
} 
regionales para incluirlos en el Plan Nacional de Desarrollo, coordinar las instituciones a nivel nacional, departamental y municipal; entre las segundas, integrar las entidades territoriales de cada región, fortalecer la capacidad y autonomía de las regiones, participar en el Presupuesto de Inversión Nacional. En el balance de la experiencia de los CORPES aparecen mayoritariamente puntos positivos alrededor de los procesos de integración territorial, y se evidencian al mismo tiempo bloqueos institucionales o incongruencias técnicas aún existentes (Vasco, 1996). En todo caso, esta experiencia ha servido de base para pensar política y técnicamente la territorialización de la planificación que ha tenido luego los avances que acabamos de mencionar.

En cambio, el objetivo de apalancamiento de los recursos de las entidades territoriales entre ellas a través del desarrollo de la asociatividad territorial ha sido mucho menos exitoso (De la Torre, 2016). Poniendo entre paréntesis las dinámicas de organización de los espacios urbanos metropolitanos de los ańos ochenta, cuyos logros son disímiles y localizados en materia de integración territorial hasta el momento $^{16}$, el proceso de asociatividad territorial en
Colombia tiene su principal manifestación en las asociaciones de municipios que existen en el ordenamiento jurídico desde $1975^{17}$. Y aunque su figuración en el paisaje político-administrativo colombiano no es del todo ilusoria, pues en 2010 la cobertura municipal del fenómeno asociativo superaba el $50 \%{ }^{18}$, las estructuras asociativas municipales tienen graves carencias de recursos que generan dificultades para alcanzar sostenibilidad en los acuerdos políticos que han permitido su creación ${ }^{19}$.

De manera más general, la asociatividad territorial sufre de la ausencia de una institucionalidad regional articuladora de la gestión pública y de la normatividad vigente que no aporta estabilidad jurídica y financiera a las entidades asociativas por las rigideces en materia de afectación de recursos. También soporta la incidencia negativa de los ciclos políticos en la perpetuación de las iniciativas de integración territorial. Estos son algunos de los problemas a los cuales buscaba responder la Ley Orgánica de Ordenamiento Territorial (LOOT) del 28 de julio de 2011, que aún está por encontrar su plena expresión en la acción del Gobierno nacional y de los representantes de las entidades territoriales.

16 Hoy hay cinco Áreas Metropolitanas registradas en el país: Valle de Aburrá (9 municipios alrededor de Medellín), la más antigua; Centroccidente (2 municipios alrededor de Pereira); Bucaramanga (3 municipios alrededor de Bucaramanga); Barranquilla (4 municipios alrededor de Barranquilla), y Cúcuta (3 municipios alrededor de Cúcuta).

17 Ley 1 de 1975, que reglamentó el inciso 3 del artículo 198 de la Constitución de 1886.

18 Según los registros que lleva la Federación Colombiana de Municipios, en términos cuantitativos, a finales de 2009 estaban registradas 58 asociaciones de municipios, de las cuales 54 estaban en funcionamiento y 4 en liquidación. En total, 581 municipios en 20 departamentos pertenecían a estas estructuras.

19 Un informe de la Contraloría General de la Nación de junio de 2010 ("Situación actual de las asociaciones de municipios en Colombia") plantea también en el campo político una ausencia de liderazgo de la mayoría de los directores ejecutivos de estas organizaciones o una falta de experiencia y conocimiento del objetivo de la asociatividad territorial. 
La implementación de estas dos estrategias de reorganización de la acción pública (la territorialización de la planificación y el fomento de la asociatividad territorial) muestran a la vez los límites de la organización territorial del Estado y de la práctica administrativa. La implementación de una estrategia de coordinación entre niveles de gobierno se impone con verdadera urgencia. Esta necesidad se manifiesta considerando, bajo un ángulo estrictamente financiero, que en la descentralización de los años ochenta y noventa no hubo redistribución integral de los recursos públicos y, en particular, de los productos fiscales. El poder tributario de los gobiernos locales sigue siendo muy débil, por lo cual sus márgenes de maniobra y de decisión, más aun que su capacidad financiera, distan mucho de ser óptimos o efectivos. Y aunque la reforma del Sistema General de Regalías aumentó el emprendimiento de las entidades territoriales, la descentralización como proceso de largo alcance, por haber estimulado una mayor visibilidad de la gestión pública en el ámbito regional, incrementó la dependencia respecto al nivel central en materia de recursos (Bergvall, Charvit, Kraan y Merk, 2006).

Como vemos, el contexto actual conduce a una concepción del ordenamiento territorial muy alejada del pulso bipolar centro-periferia y de la reivindicación incremental de autonomía de otras épocas. De cara al futuro, los dos mayores retos para construir una gobernanza territorial inclusiva son el buen manejo de las interacción entre los diferentes niveles de gobierno y la eficaz coordinación de los representantes electos (nacionales y locales) y las administraciones (centrales y descentralizadas).

\section{GOBERNANZA TERRITORIAL} MULTINIVELES Y CONTRACTUALIZACIÓN

Un aspecto esencial del manejo actual del desarrollo regional es la importancia que se le da a la organización de una coordinación interinstitucional que combine mecanismos de acción colectiva y dispositivos de delegación. De cara al futuro, se han desarrollado nuevos instrumentos de coordinación horizontal, de cooperación y de participación en la asignación de los recursos necesarios para el desarrollo. Se trata principalmente de esa categoría de herramientas y procedimientos institucionales que generalmente se asocian al paradigma de la gobernanza multiniveles (Dubois, 2009). La gobernanza territorial multiniveles cubre todas las situaciones de cooperación entre poderes públicos y entre actores privados y ciudadanos que no están totalmente establecidos por la jerarquía institucional, y que corresponden a la construcción, administración o representación de los territorios en los que vive la población (Pasquier, Simoulin y Weisbein, 2007).

Uno de los dispositivos emblemáticos de la gobernanza territorial es la contractualización, es decir, la utilización de los denominados "contratos de acción pública" (Gaudin, 2014), de los cuales hace parte la figura de los Contratos Plan, creada en Colombia en 2011. Sus fuentes legislativas son la Ley 1450 del 16 de junio 2011, que expidió el Plan Nacional de Desarrollo 2010-2014 "Prosperidad para todos" (art. 8), y la LоOт del 28 de junio 2011 (arts. 9, 12, 13, 14 y 18) ${ }^{20}$. La medida tiene una clara filiación con la figura francesa de los Contrats de Plan Etat-Région (CPER) que 
inauguraron en los primeros ańos de la descentralización (1983-84) una transformación de la concepción del ordenamiento territorial que conduciría, en 1992, a la desaparición de la planificación nacional al final del $\mathrm{X}^{\circ}$ Plan (Moulin, 2002).

La categoría de los contratos de acción pública se diferencia de los "negocios jurídicos" (contratos privados y convenios administrativos), pues tiene como objetivo concertar esfuerzos de las diferentes entidades públicas para la planeación integral del desarrollo, con un enfoque a mediano plazo, priorizando proyectos de los planes nacionales, departamentales y municipales de desarrollo (González, 2013). Hay que considerar los contratos de acción pública como un instrumento político de coproducción de proyectos de desarrollo territorial entre actores que representan diferentes niveles de gobierno. En su elaboración y ejecución, cuatro componentes están íntimamente ligados (Gaudin, 1999):

- un contrato, es decir una matriz legal y una técnica jurídica, a la que recurren las autoridades públicas,

- dentro del marco de una apuesta que busca generar un diálogo interinstitucional y procedimientos de ejecución y seguimiento propios que determinan

- una acción pública,
- producto de un acuerdo entre un conjunto de actores públicos (y eventualmente privados).

En la práctica político-administrativa, su elaboración genera un proceso en cuatro etapas:

- Una fase preliminar de diagnóstico territorial que delimita el ámbito geográfico de intervención con sus características distintivas. Es una tarea que permite determinar las fronteras del territorio de acción y explicitar sus fortalezas y debilidades. Esta misión la pueden asumir los actores involucrados en los proyectos o externalizarse.

- Una negociación entre actores de los diferentes niveles de gobierno que finaliza con la adopción consensuada de una serie de objetivos de acción que pueden ser una inversión, un proyecto o un programa estructurado de proyectos de desarrollo.

- La formulación de un compromiso sobre las contribuciones conjuntas de las partes implicadas en el acuerdo para la realización de los objetivos, bajo la forma de aportes financieros o del apalancamiento de recursos humanos o técnicos, y un calendario de realización.

- Por último, las partes suscriben un texto que formaliza los compromisos. A partir

20 En la reglamentación asociada a la aplicación de la medida figuran inicialmente el Decreto 819 del 25 de abril 2012, "por el cual se dictan disposiciones sobre la elaboración e implementación de los Contratos Plan", y dentro del PND 2014-2018, los artículos 198 (Contratos Plan) y 199 (Mecanismos para la ejecución de los Contratos Plan). 
de ese documento vinculante que perfecciona el acuerdo de voluntades y que define igualmente los arreglos institucionales que regulan las relaciones entre los firmantes, se inicia la ejecución de los programas y proyectos de desarrollo que se han fijado.

Una de las particularidades de estos pactos de inversión o de intervención es que se aplican al territorio que determinan los propios actores que suscriben el acuerdo contractual. Vale la pena indicar al respecto que, si el proceso político que llevó a la implementación de los Contratos Plan en Colombia a partir de 2012 condujo a la firma de acuerdos entre el Gobierno nacional y los departamentos, ninguna de las dos leyes que fundamenta la medida había previsto esta "coloración departamental" del instrumento.

En el caso de Colombia, la escala de gobernanza departamental se impone como resultado de un juego de actores implicados en la creación-importación de la medida Contratos Plan. En un proceso que va del año 1996, cuando la figura de los CPER franceses llega "en las maletas" de quien sería director de gobierno y gestión territorial en el ministerio del interior del gobierno de Andrés Pastrana ${ }^{21}$, hasta la adopción de la medida en la Ley del PND 2010-2014, pasando por la larga elaboración de la LOOT $^{22}$ que aclimata el modelo francés, se consolida una red de actores que actúan como una "coalición de causa" (Advocacy Coalition Framework - ACF) (Jenkins-Smith y Sabatier, 1999). Esa red de actores, que interviene particularmente de 2011 a 2015 en las fases de operacionalización y de implementaciónpiloto de la medida, va a privilegiar una concepción del nuevo instrumento en la cual se pone de manifiesto:

- Que el CP se adapta particularmente a territorios "virtuales" en vía de construcción (regiones, conjuntos intercomunales) o en crisis (municipios rurales, de frontera, zonas de fuerte incidencia del conflicto).

- Que la preparación de los acuerdos estratégicos de los CP supone que los actores adopten mecanismos colaborativos de gestión (concertación, negociación explícita, cofinanciación, etc.) con los cuales se puede profundizar la descentralización territorial en un doble movimiento de distanciación del Estado-centro (en lo que está en juego desde el punto de vista de gobernanza del desarrollo) y de empowerment local.

Hemos investigado la incidencia de este proceso de policy making en los diferentes territorios de la fase piloto de implementación de la medida. Los resultados de la investigación muestran que el proceso de policy transfer (Do-

21 Quien lo asimila como alumno de la Escuela Nacional de Administración (ENA) francesa entre 1996 y 1997.

22 En particular, en el Proyecto de Ley 041 del 26 de julio de 2001, el octavo de los 13 proyectos de ley que se presentaron ante el parlamento entre 1992 y 2011. 
lowitz y Marsh, 1996) del cual surge la creación de la figura de los Contratos Plan colombianos se inscribe en la larga evolución del paradigma de la planificación para el desarrollo del país ${ }^{23}$.

\section{A MANERA DE CONCLUSIÓN: ¿CONTRACTUALIZAR LA DESCENTRALIZACIÓN EN EL POSCONFLICTO?}

Los Contratos Plan colombianos llevan cinco años de implementación experimental en siete territorios piloto: Atrato Gran Darién (4 municipios entre los departamentos de Córdoba, Chocó y Antioquia); Cauca (13 municipios); Nariño (14 municipios); sur del Tolima (9 municipios); Boyacá (117 municipios); Santander (la totalidad de los 87 municipios); Arauca (7 municipios). En su implementación actual aparecen como pactos políticos entre el Gobierno nacional y las entidades territoriales, iniciados y conducidos por el DNP, en los cuales priman objetivos de planeación: optimizar el impacto de la inversión pública en las regiones y permitir la buena ejecución del Plan Nacional de desarrollo y de los planes de desarrollo de las entidades territoriales. La inversión total proyectada para estos 7 pilotos fue de cerca de 12,6 billones de pesos en tres años (2013-2015). La nación aportó cerca del $78 \%$ de los recursos ${ }^{24}$ y las entidades territoriales el $22 \%$ restante $^{25}$. Aunque la evaluación de los pilotos está por finalizar, queda claro que la utilización del instrumento sí fortaleció la colaboración multiniveles y facilitó la concurrencia de recursos y fuentes de financiación de proyectos que generaron consensos, pues resultaban de una negociación explícita publicitada. También se pudo observar que es necesario ajustar su perímetro de intervención para instalar un ciclo virtuoso de gobernanza multiniveles más inclusivo, focalizando los recursos de los diferentes actores del desarrollo en los programas y proyectos con mayor impacto social y económico para cada territorio (Castro, 2016).

Un punto importante de esta experimentación es que la geografía de los territorios-pilotos, producto de la participación voluntaria de los ejecutivos locales firmantes, permitió llevar a las poblaciones de diferentes zonas rurales del país una oferta coordinada de equipamientos, infraestructura y servicios, en condiciones que no se habían dado hasta ahora. Algunas de esas zonas, como el sur del Tolima, el norte del Cauca, Narińo y el área del Gran Darién en su totalidad, forman parte de esos 187 municipios en los que la incidencia del conflicto interno ha sido considerada como "alta" y "muy alta"

\footnotetext{
23 Se trata de un programa de investigación que conduzco actualmente dentro del marco de un acuerdo interuniversitario entre las universidades Montpellier III (ART-Dev) y de los Andes (CIDER) y cuyos resultados serán publicados en el segundo semestre de 2017.

24 Provenientes del Presupuesto General de la Nación y del Sistema General de Participaciones, pero igualmente recursos adscritos al DNP.

25 La mitad proveniente del Sistema General de Regalías (51\%) y el resto de los recursos propios de las entidades territoriales.
} 
para el Departamento Nacional de Planeación (DNP, 2015).

Apoyándose en esa particularidad, el Gobierno nacional identificó el dispositivo Contrato Plan, renombrándolo Contrato Paz, como uno de los "vehículos para la implementación de las acciones del posconflicto". Los Contratos Paz se articularán con los programas de desarrollo con enfoque territorial (PDET) ${ }^{26}$, y los dos mecanismos son los pilares del componente territorial de la implementación de los acuerdos de $\mathrm{paz}^{27}$.

A través de los Contratos Plan-Paz, el enfoque contractual se afianza entonces como una política pública consolidada en Colombia. Para implementarla, el gobierno nacional ha determinado recursos específicos, con la constitución del Fondo Regional para los Contratos $\mathrm{Plan}^{28}$, y nuevas reglas de implementación y financiación ${ }^{29}$. Por otra parte, en el despliegue de la segunda generación de Contratos Paz figuran ocho zonas ${ }^{30}$ que cubren una superficie cercana a la mitad del territorio nacional. Ya han sido firmados dos de los nuevos Contratos Plan (Montes de María y Meta, Caquetá, Guaviare), y la presencia en el nuevo panel de cinco territorios de la primera generación ${ }^{31}$ permite apoyarse en la experiencia acumulada para organizar una dinámica amplificada del proceso de innovación que se inició en 2012, con la experimentación de los Contratos Plan Pilotos.

Si descentralizar es introducir la dimensión territorial en las políticas públicas, cada proceso descentralizador tiende a ser forzosamente aleatorio e imprevisible, o, como dice un reciente informe del think tank francés Terra Nova "un fenómeno sin modelo de referencia" (Davezies y Morvan, 2016, p. 14). Sin embargo, el hecho de que la implementación de la estrategia de desarrollo territorial para el posconflicto haya adoptado la forma contractual, crea un precedente. En los Contratos Paz, el Gobierno nacional busca movilizar no solo los recursos de las entidades territoriales que administran los ejecutivos locales (gobernadores y alcaldes), sino la participación de los otros actores locales del desarrollo (empresarios, actores sociales y protagonistas del conflicto). Se confirman asílas premisas del proceso que, desde hace algunos años, como lo hemos mostrado, hizo entrar los principios de la gobernanza territorial multiniveles en la planificación y en el manejo del desarrollo territorial.

De esta manera nos parece que se plantean igualmente las condiciones para consolidar una nueva etapa de la descentralización con énfasis en los mecanismos de la gobernanza territorial multiniveles, en la cual, a la ima-

26 Estos últimos son un modelo de intervención acordado entre el Gobierno nacional y las FaRC en el punto número 1, "Hacia un nuevo campo colombiano: Reforma Rural Integral", de los acuerdos de La Habana.

27 Proyecto de documento conpes en preparación, "Estrategia de posconflicto en Colombia", borrador del 7 de julio de 2016. Recuperado de https://colaboracion.dnp.gov.co/CDT/Conpes/Econ \%C3\%B3micos/3867.pdf

28 Decreto 240 del 4 de mayo 2016, que crea el Fondo Regional para los Contratos Plan.

29 Decreto 1675 del 21 octubre 2016, que define las reglas de elaboración y de financiación de los Contratos Plan.

30 Montes de María, La Guajira, Norte de Santander (Catatumbo), Guainía, Meta, Caquetá, Guaviare, Amazonas, Putumayo, Narińo, Cauca, Valle del Cauca, Atrato Gran Darién.

31 Atrato Gran Darién, Arauca, Narińo, Cauca, sur del Tolima. 
gen de los diálogos que se desarrollaron en La Habana, la priorización y el manejo de los recursos públicos sean el resultado de consensos o de compromisos de todos, alcanzados en la práctica de una negociación explícita. De tal manera que, de cara al futuro, descentralizar sea contractualizar.

\section{REFERENCIAS}

Auriac, F. y Brunet, R. (1986). Espaces, jeux et enjeux. Paris: Fayard.

Bergvall, D., Charvit, C., Kraan, D. y Merk, O. (2006). Intergovernmental grants and decentralized public spending. OECD Journal of Budgeting, 5 (4).

Bird, R. y Wiesner, E. (dirs.) (1982). Finanzas intergubernamentales en Colombia. Bogotá: DNP.

Castro, M. F. (2016). Un instrumento para mejorar la calidad de la inversión e impulsar el desarrollo regional. En Los Contratos Plan: un instrumento para la descentralización y el desarrollo de las regiones (pp. 15-40). Bogotá: DNP.

Chambron, N. y De la Torre, L. A. (1994). La décentralisation infracommunale comme outil de gestion urbaine: l'exemple de Bogotá. En Colombie, Cahiers d'Amérique Latine (pp. 141160). Paris: IHEAL.

Cruz, J. G. (2009). Gerencia pública en Colombia, haciendo énfasis en el actual Gobierno. Entramado, 5 (2), 152-163.

Chamorro, L. H. (1997). Balance del proceso de conformación de regiones en Colombia: los CORPES. Planeación y Desarrollo, 28 (4), 115-150.

Castro, J. (2003). La cuestión territorial. Bogotá: La Oveja Negra.
Castro Forero, A. (2014) Balance de la descentralización en Colombia. Informe para la Escuela Superior de Administración ESAP. Documento no publicado.

Davezies, L. y Morvan, Y. (2016). Pour une grammaire de la décentralisation. Paris: Positions, Fondation Terra Nova.

De la Torre, L. A. (2016). El desafío frente a las insuficiencias de la coordinación interinstitucional. En Los Contratos Plan: un instrumento para la descentralización y el desarrollo de las regiones (pp. 51-66). Bogotá: DNP.

Departamento Nacional de Planeación (DNP) (2008). Propuestas para la formulación de politicas regionales diferenciadas. Bogotá: DNP.

Departamento Nacional de Planeación (DNP) (2013). Guía para la estructuración de Áreas de Desarrollo Territorial alrededor de ejes de integración y corredores de desarrollo. Bogotá: DNP.

Departamento Nacional de Planeación (DNP) (2015). Indice de vulnerabilidad territorial: resultados 2008-2012. Bogotá: Dirección de Justicia, Seguridad y Gobierno, Subdirección de Seguridad y Defensa.

Dubois, J. (2009). Les politiques publiques territoriales. La gouvernance multi-niveaux face aux défis de l'aménagement. Rennes: Presses Universitaires de Rennes.

Dolowitz, D. y Marsh, D. (1996). Who learns what from whom: a review of Policy Transfer Studies. Political Studies, xLIV, 343-327.

Faure, A. (2011). Action publique territoriale. En Romain, P. et al. Dictionnaire des politiques territoriales (pp. 27-33). Paris: Presses de Sciences Po (P.F.N.S.P.) “Références",

Franco Vargas, M. H. y Cristancho Escobar, F. (2012). El federalismo fiscal y el proceso de descentralización fiscal en Colombia. Estudios de Derecho, LXIX. (154), 235-262. 
Garay Salamanca, L. J. y Salcedo-Albarán, E. (2010). Crimen, captura y reconfiguración cooptada del Estado: cuando la descentralización no contribuye a profundizar la democracia. En 25 años de descentralización en Colombia. Bogotá: Konrad Adenauer Stifttung.

Gaudin, J. P. (1999). Gouverner par contrat. L'action publique en question. Paris: Presses de la Fondation Nationale de Sciences Politique.

Gaudin, J. P. (2014). Contrats. La notion et le développement des contrats d'action publique. En Boussaguet, L. et al. Dictionnaire des Politiques Publiques (pp. 164-17). Paris: Presses de Sciences Po (P.F.N.S.P.).

Gilly, J. P. y Torre, A. (2000). Dynamique de proximité. Paris: L'Harmattan, Collection Emploi, Industrie et Territoire.

González Salas, E. (1997). El laberinto institucional colombiano, 1974-1994. Bogotá: Universidad Nacional - ESAP - FESCOL.

Gutiérrez Sanín, F. (2010). Instituciones y territorio. La descentralización en Colombia. En 25 años de descentralización en Colombia. Bogotá: Konrad Adenauer Stifttung.

González Franco, D. (2013). Consideraciones jurídicas sobre la figura de los Contratos Plan en Colombia. En Estupiñán, L. y Restrepo, M. A. (eds.). Asociatividad territorial: enfoque comparado y análisis en el nuevo contexto de la organización territorial colombiana (pp. 307-337). Bogotá: Colección Textos de Jurisprudencia, Editorial Universidad del Rosario.

Jenkins-Smith, H. y Sabatier, P. (1999). The advocacy coalition framework: An assessment. En Sabatier, P. (ed.). Theories of the Policy Process. Boulder: Westview Press.
Lamara, H. (2009). Les deux piliers de la construction territoriale : coordination des acteurs et ressources territoriales. Revista Développement durable et territoires Varia.

Leal Buitrago, F. (1984). Estado y politica en Colombia. Bogotá: Cerec y Siglo xxi Editores.

Leal Buitrago, F. y Dávila Ladrón de Guevara, A. (1991). Clientelismo. El sistema politico y su expresión regional. Bogotá: Instituto de Estudios Políticos y Relaciones Internacionales, Universidad Nacional y Tercer Mundo.

Le Galès, P. (2010). Gouvernance. En Boussaguet, L. et al. Dictionnaire des Politiques Publiques (pp. 299308). Paris: Presses de Sciences Po (P.F.N.S.P.).

Maldonado Copello, A. (2011). La descentralización territorial en Colombia: situación y perspectivas de politica. Bogotá: FEsCOL.

Maldonado Copello, A. (2012). Los límites de la descentralización territorial: en caso de Colombia 1991-2008. U. Complutense de Madrid: Memoria para optar al grado de doctor en Ciencias Políticas y Sociología.

Marcou, G. (ed.) (2008). La descentralización y la democracia local en el mundo, Primer Informe Mundial. Barcelona: Ciudades y Gobiernos Locales Unidos (CGLU).

Melo, J. O. (2011) Éxitos y debilidades de la Constitución de 1991. Razón Pública. Recuperado de http://www.razonpublica.com/index.php/ component/contact/contact/23.html

Moulin, O. (ed.). (2002). Les Contrats de Plan EtatRégion. Paris: La Documentation Française.

Negrier, E. (2007). Penser la contingence territoriale. En Negrier, E. y Faure, A. (dirs.). Les politiques publiques à l'épreuve de l'action locale. Critiques de la territorialisation. Paris: L'Harmattan. 
Pasquier, R., Simoulin, V. y Weisbein, J. (ed.) (2007). La Gouvernance territoriale. Pratiques, discours et théories. Paris : LGDJ.

Rojas, F. y Moncayo, V. M. (1989). Tendencias de reinstitucionalización del Estado en Colombia. En Medellin, P. (ed.). La reforma del Estado en América Latina (pp. 243-302). Bogotá: FESCOL.

Tirado Mejía, Á. (1983). Descentralización y centralismo en Colombia. Bogotá: Fundación Naumann, Serie Monografías de Ciencias Sociales y Política, Oveja Negra.

The World Bank Group (s.f.). What, Why, and Where. Recuperado de http://www1.worldbank.org/ publicsector/decentralization/what.htm\#2
Vasco, M. (1996). Sistema de inversión pública y descentralización: el caso colombiano. Santiago de Chile: Instituto Latinoamericano y del Caribe de Planificación Económica y Social ILPes.

Velásquez, F. (2006). Seminario "20 años de descentralización en Colombia: presente y futuro". Bogotá.

Weber, M. (1922). Economía y sociedad. Elementos de sociología comprehensiva. México: Fondo de Cultura Económica.

Wiesner, E. (2003). La descentralización, la estabilidad macroeconómica y la integración económica regional: enlaces de politica y mecanismos de transmisión. Bogotá: BID-Instituto para la Integración de la América y El Caribe. 